\title{
Developments in an HF Nowcasting Model for Trans-Polar Airline Routes
}

\author{
H.A.H. Al-Behadili*(1), E.M. Warrington ${ }^{(1)}$, A.J. Stocker ${ }^{(1)}$, D.R. Siddle ${ }^{(1)}$, F. Honary ${ }^{(2)}$, \\ N.C. Rogers ${ }^{(2)}$,N.Y. Zaalov ${ }^{(3)}$, D.H. Boteler ${ }^{(4)}$ and D.W. Danskin ${ }^{(4)}$ \\ (1) Department of Engineering, University of Leicester, Leicester, UK. \\ (2) Department of Physics, Lancaster University, Lancaster, UK. \\ (3) Department of Radio Physics, Faculty of Physics, Saint Petersburg State University, Saint Petersburg, Russia
}

(4) Natural Resources Canada, Ottawa, Canada.

\begin{abstract}
HF communications can be difficult in the polar regions since they are strongly influenced by space weather events. Airline communications within the polar regions rely on $\mathrm{HF}$ communications and improved nowcasting and forecasting techniques in support of this are now required. Previous work has demonstrated that ray tracing through a realistic, historical ionosphere provides signal coverage in good agreement with measurements. This paper presents an approach to providing a real-time ionospheric model by assimilating TEC measurements and validates it against observations from ionosondes.
\end{abstract}

\section{Introduction}

The number of commercial airline flights taking northern polar routes has increased from around 100 in 2000 to more than 12,000 in 2014. Since VHF communications with air traffic control centres are not available over the pole, and most aircraft are not equipped for satellite communications (which are, in any case, not available via geostationary satellites poleward of $82^{\circ} \mathrm{N}$ ), the aircraft rely on communications within the HF band. While such frequencies support "over the horizon" communication, the polar regions are particularly difficult since the polar ionosphere is strongly affected by space weather conditions (e.g. solar flares, solar wind, etc.). Ongoing work, which uses a ray-tracing model $[1,2]$ to estimate the signal coverage $[3,4]$, has previously been reported. In this model, a background ionosphere is generated, which is then perturbed with electron density variations associated with the presence of various high latitude ionospheric features (patches, arcs, auroral oval irregularities and the mid-latitude trough). The effect of D-region absorption is also incorporated. In this paper, we present work that improves and validates the ionospheric model that is used in our HF prediction code against results from a broad range of ground stations (more than $60)$ distributed around the world.

\section{Description of the HF Prediction Model}

There are three particular features that have significant influence on high-latitude HF radio propagation that need to be accounted for in the ionospheric models:
1. The background ionosphere. In our model this is based on the International Reference Ionosphere (IRI), initially, with inputs from non-real time sources [5]. Several authors have assimilated real-time inputs, such as GIRO [6] and GPS data [7] into the IRI to improve its accuracy.

2. Electron density enhancements due to the presence of polar cap patches and arcs [1,2], and the electron density distribution within the mid-latitude trough [8], which their influences on directional characteristics were reported by $[9,10]$.

3. The effect of intermediate and high-level absorption in the D-region during space weather events [11].

In our research, a method has been developed to make changes to the IRI to improve the real-time accuracy and to make the system readily adaptable for automated running. Two input indices have been utilized to derive the adjusted background ionosphere: the global ionospheric index (IG) and the sunspot number index (RZ) that are usually input as 12 month running means. Although IG and RZ are global constants, by varying them over longitude, latitude and time, the IRI can be forced to represent a particular state of the ionosphere. This was achieved by determining IG and RZ values such that measured slant TEC values matched those produced by the IRI and then using the resultant ionospheric parameters (foF2, hmF2, etc.) to define the background ionosphere in the raytracing model. Whilst there is a lack of information to deal with the IG and RZ parameters separately, their relationship has been fixed to that given by fitting a curve to the historical values relating the two parameters [3].

In order to estimate the ray paths from the transmitter to the receiver, via the modelled ionosphere outlined above, a numerical ray tracing code [12] has been employed. The received signal strength is then calculated by taking into account the transmitted power, antenna gains, and HF absorption within the D-region $[13,14,15]$.

\section{Results of Tests}

In order to generate a background ionosphere based on the IRI, but adjusted for real-time inputs, the following method has been adopted. Measurements of sTEC are 
taken from about 60 GPS stations located at mid and high latitudes. The IG and RZ values are adjusted for each latitude and longitude until sTEC values derived from the IRI match the observations. The other ionospheric parameters are then derived from the IRI. In order to test this approach, the foF2 values derived from the IRI driven by the slant TEC from 12 GPS stations are compared with the observed values of foF 2 from 12 nearby ionosondes. An example of outcome this process for a single midlatitude station is presented in Figure 1.

In the left hand panel, the IG and RZ values required to obtain agreement between the sTEC observed by GPS and that derived from the IRI are presented together with the standard values used in the IRI. For this example, the IG and $\mathrm{RZ}$ values are higher than the monthly values usually used by the IRI and vary with time. In the right hand panel, the foF2 values derived from the IRI are lower than those observed by the ionosonde by a few $\mathrm{MHz}$ Once TEC is used to drive the IRI, then the outcome is improved with a much closer agreement. The RMS errors between the observed foF 2 and the values derived from the IRI (standard and TEC driven) for 12 ionosonde stations are presented in Figure 2. Here it is evident that the RMS error is usually less for the TEC driven IRI, i.e. the performance is improved, for all of the selected stations for this day.

In order to further assess the performance of the method, the RMS errors for each station over 3 hour LT bins were used to classify whether the TEC driven IRI provided an improvement or whether there was no change in foF2 compared to the standard IRI value. Figure 3 shows the occurrence statistics of the improved and no change cases for all 12 stations. There was an improvement in at least $80 \%$ of cases for all times of day, while the period from 915 LT shows improvements of $90 \%$ or more.
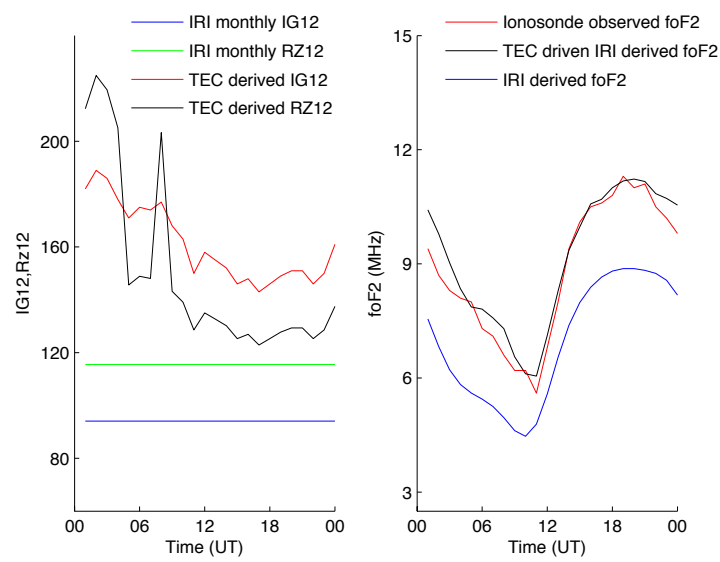

Figure 1. Left: the values of IG and RZ required to give good agreement between measured sTEC and IRI-derived sTEC for the GPS receiver located at Bar Harbor, USA. Right: foF2 values obtained from the IRI with the sTECderived IG and RZ values compared with the measured foF2 values nearby Millstone Hill, USA for 1 April 2014.
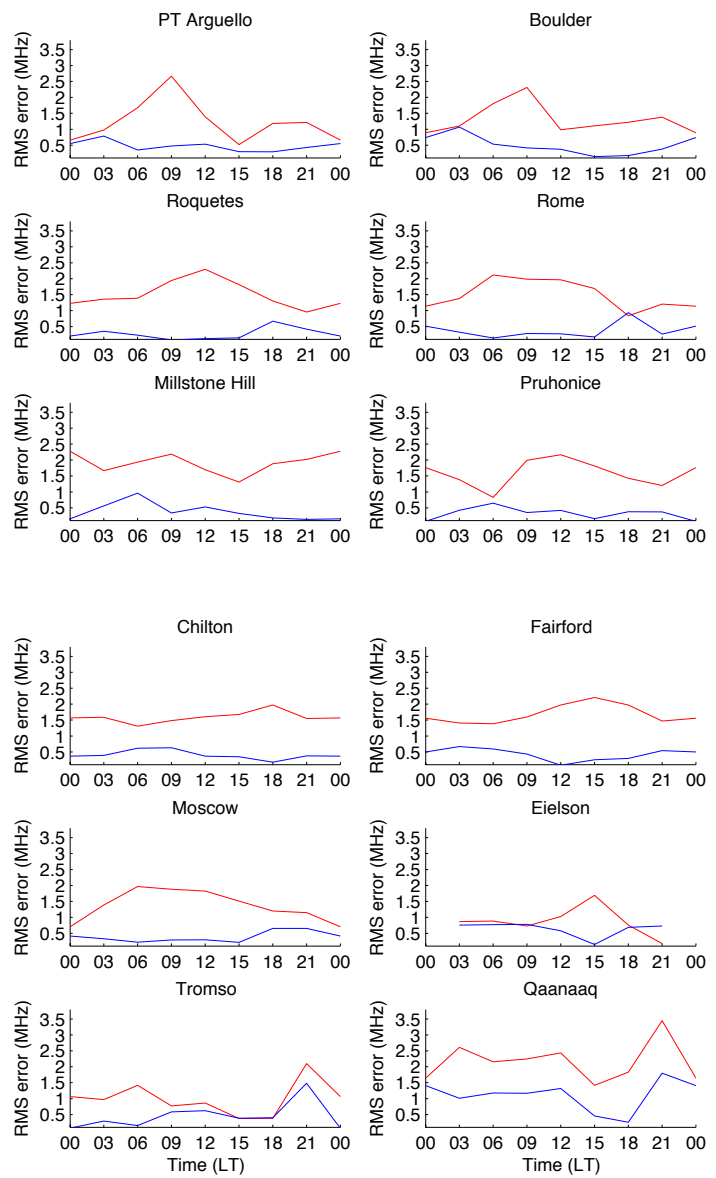

Figure 2. The RMS errors of the foF 2 values using the monthly IRI values (red lines) and the values obtained from the IRI with the sTEC-derived IG and RZ values (blue lines) for 1 April 2014.

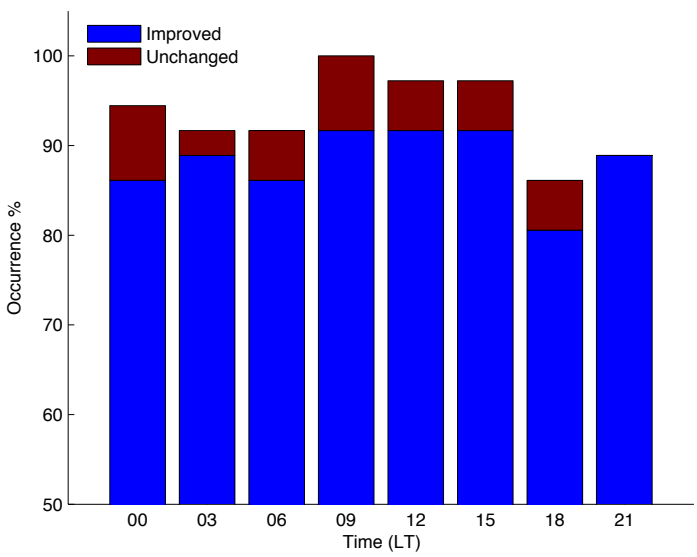

Figure 3. Histogram of the percentage of cases where foF2 values were improved by using the sTEC-derived IG and RZ as input to the IRI and where the values remained unchanged to within $\pm 0.2 \mathrm{MHz}$ as a function of local time. The data were binned into $3 \mathrm{~h}$ periods centred on the indicated time for all 12 selected ionosonde stations for 1 April 2014. 
A mapping function was used to describe the variation of foF2 over various geographic regions, fitting the curves and smoothing of IG and RZ changes over latitude and longitude in order to generate a background ionosphere.

Coverage plots for the same date (i.e. 1 April 2014) using our previous model of the background ionosphere and the new model are compared in Figure 4. While agreement is obtained between the two at some places, there are differences that are evident in the left of the figure and around the transmitter position. More tests are required particularly with HF directional measurements and HF coverage predictions using well-known tools in order to validate the model and to provide a nowcast of $\mathrm{HF}$ ionospheric propagation

\section{Concluding Remarks}

This paper introduced a method for improving the prediction of foF 2 over a number of geographic locations by using observations of sTEC to modify monthly IG and RZ values and hence the output from the IRI. The method provides an improvement in the modelled value of foF2 compared to the observed value in at least $80 \%$ of the tested cases and at times centred on local midday upwards of $90 \%$. However, caution must be exercised since it remains to investigate whether this method provides the same level of improvement across a wider number of cases (e.g. different seasons). In the short-term, the model will now be developed to incorporate the sTEC observations in real-time to provide nowcasts of the background ionosphere, while on a longer time-scale, space weather records will be assimilated in order to provide forecasts.

A mapping function based on an interpolation technique has been employed to generate a global grid of IG and RZ indices. This has then been used as input to the IRI to produce a background ionosphere and hence a map of HF signal strength.

\section{Acknowledgements}

The authors are grateful to the EPSRC for their support of this research through grants EP/K008781/1 and $\mathrm{EP} / \mathrm{K} 007971 / 1$. The first author is also grateful for Ministry of Higher Education and Scientific Researches and the University of Misan/Iraq for funding his scholarship. This research used the ALICE High Performance Computing Facility at the University of Leicester.

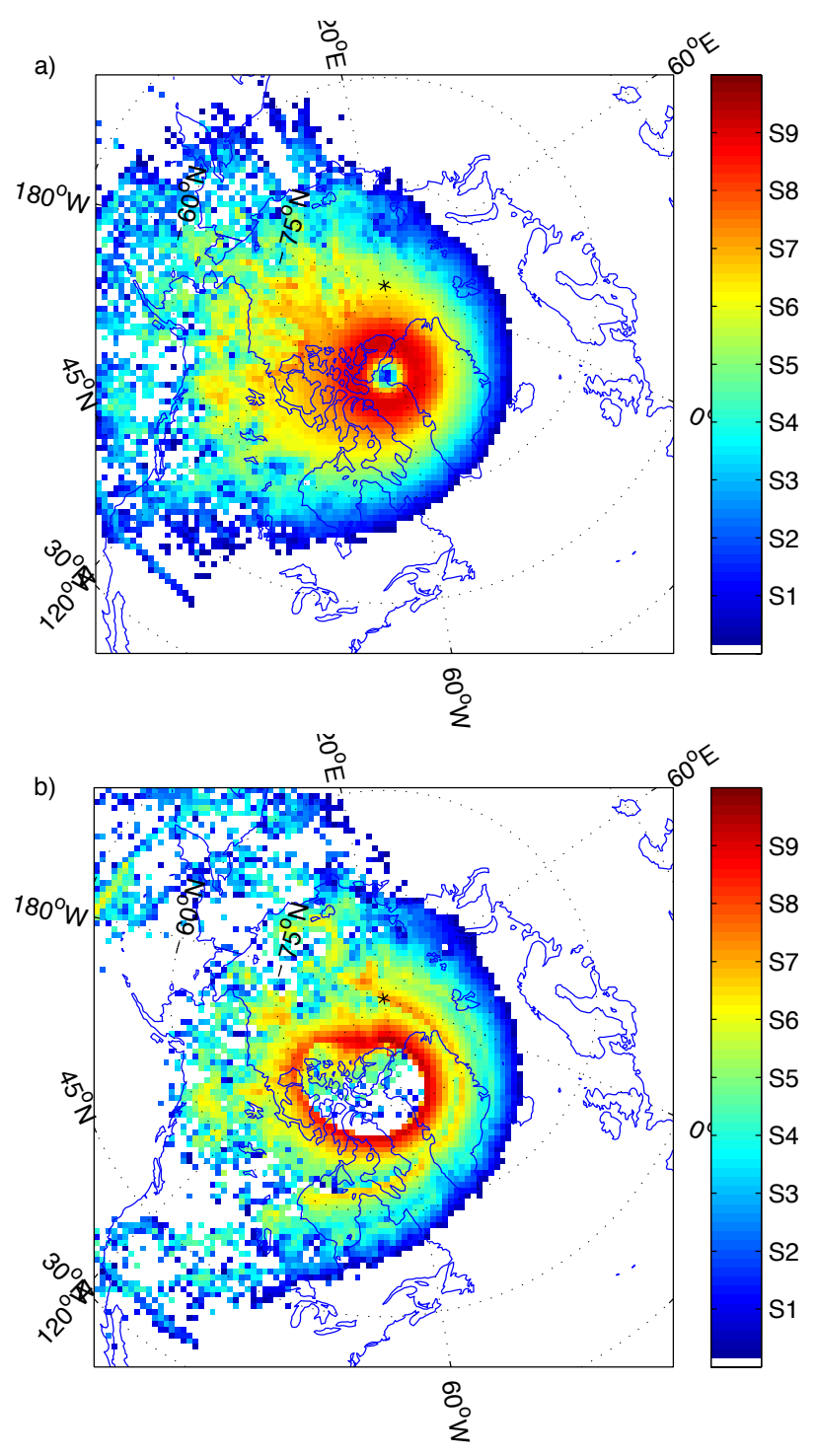

Figure 4. Predicted signal coverage at $7.0 \mathrm{MHz}$ for a transmitter located in Qaanaaq for 12:00 UT on 1 April 2014 using (a) the previous ray-tracing model $[3,4]$ (b) the IRI-based model. The colours indicate the received signal strength in $\mathrm{S}$ units. 


\section{References}

1. N.Y.Zaalov, E.M. Warrington and A.J. Stocker, "Simulation of off- great circle HF propagation effects due to the presence of patches and arcs of enhanced electron density within the polar cap ionosphere," Radio Science, 38, 3, 1052, June 2003, doi: $10.1029 / 2002$ RS002798.

2. N.Y.Zaalov, E.M. Warrington and A.J. Stocker, "A ray-tracing model to account for off-great circle $\mathrm{HF}$ propagation over northerly paths," Radio Science, 40, 4, RS4006, July 2005.

3. E.M. Warrington, A.J. Stocker, D.R. Siddle, J. Hallam, H.A.H. Al-Behadili, N.Y. Zaalov, F. Honary, N.C. Rogers, D.H. Boteler and D.W. Danskin, "Near realtime input to a propagation model for nowcasting of HF communications with aircraft on polar routes," Radio Science, 51, July 2016, pp. 1048-1059, doi: $10.1002 / 2015 R S 005880$

4. E.M. Warrington, N.C. Rogers, A.J. Stocker, J. Hallam, D.R. Siddle, H.A.H. Al-Behadili, N.Y. Zaalov, F. Honary, D.H. Boteler and D.W. Danskin, "Progress towards a propagation prediction service for $\mathrm{HF}$ communications with aircraft on trans-polar routes," Nordic HF International Conference, Fårö Kursgård, Fårö, Gotland, Sweden, 15-17 August 2016.

5. D. Bilitza, D. Altadill, Y.Zhang, C. Mertens, V. Truhlik, P. Richards, L.-A. McKinnell and B. Reinisch, "The International Reference Ionosphere 2012 - a model of international collaboration," Journal of Space Weather and Space Climate, 4, January 2014, pp. A07, doi: 10.1051/swsc/2014004.

6. I.A. Galkin, B.W. Reinisch, X. Huang, D. Reinisch and D. Bilitza, "Assimilation of GIRO data into a real- time IRI," Radio Science, 47, RSOL07, April 2012, doi: 10.1029/2011RS004952.
7. M. Hernandez-Pajares, J.M. Juan, J. Sanz and D. Bilitza, "Combining GPS measurements and IRI model values for space weather specification," Advances in Space Research, 29, 6, 2002, pp. 949-958.

8. B.W. Halcrow and J.S. Nisbet, "A model of F 2 peak electron densities in the main trough region of the ionosphere," Radio Science, 12, 5, SeptemberOctober1977, pp. 815-820.

9. E.M. Warrington, N.C. Rogers and T.B. Jones, "Large HF bearing errors for propagation paths contained within the polar cap," IEE Proceeding Microwaves Antennas Propagation, 144, 4, August 1997, pp. 241-249.

10. N.C. Rogers, E.M. Warrington and T.B. Jones, "Large HF bearing errors for propagation paths tangential to auroral oval," IEE Proceeding Microwaves Antennas Propagation, 144, 2, April 1997, pp. 91-96.

11. T.A. Potemra, "The Empirical Connection of Riometer Absorption to Solar Protons During PCA Events," Radio Science, 7, 5, May 1972, pp. 571-577.

12. R.M. Jones and J.J. Stephenson, "A Versatile ThreeDimensional Ray Tracing Computer Program for Radio Waves in the Ionosphere," A report published by Office of Telecommunications US Department of Commerce, October 1975.

13. K. Davies, "Ionospheric radio propagation," Peter Peregrinus Ltd., London, UK, 1990, pp.214.

14. H.H. Sauer and D.C. Wilkinson, "Global mapping of ionospheric $\mathrm{HF} / \mathrm{VHF}$ radio wave absorption due to solar energetic protons," Space Weather, 6, S12002,2008, doi: 10.1029/2008SW000399.

15. N.C. Rogers and F. Honary, "Assimilation of realtime riometer measurements into models of $30 \mathrm{MHz}$ polar cap absorption," Journal of Space Weather and Space Climate, 5, A8, March 2015. 